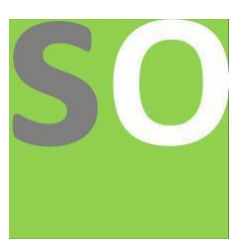

Article title: Tank Liquid Level Control using NARMA-L2 and MPC Controllers

Authors: mustefa jibril[1], Messay Tadese[2], Eliyas Alemayehu[3]

Affiliations: School of Electrical and Computer Engineering[1], Faculty of Electrical and Computer Engineering[2]

Orcid ids: 0000-0002-3165-2410[1]

Contact e-mail: mustefazinet1981@gmail.com

License information: This work has been published open access under Creative Commons Attribution License http://creativecommons.org/licenses/by/4.0/, which permits unrestricted use, distribution, and reproduction in any medium, provided the original work is properly cited. Conditions, terms of use and publishing policy can be found at https://www.scienceopen.com/.

Preprint statement: This article is a preprint and has not been peer-reviewed, under consideration and submitted to ScienceOpen Preprints for open peer review.

DOI: 10.14293/S2199-1006.1.SOR-.PP5K4PY.v1

Preprint first posted online: 31 May 2020

Keywords: NARMA-L2, Model Predictive control, Simulink, Liquid Level Control, MPC 


\title{
Tank Liquid Level Control using NARMA-L2 and MPC Controllers
}

\author{
Mustefa Jibril $^{1}$, Messay Tadese ${ }^{2}$, Eliyas Alemayehu Tadese ${ }^{3}$ \\ ${ }^{1}$ Msc, School of Electrical \& Computer Engineering, Dire Dawa Institute of Technology, Dire Dawa, \\ Ethiopia \\ ${ }^{2}$ Msc, School of Electrical \& Computer Engineering, Dire Dawa Institute of Technology, Dire Dawa, \\ Ethiopia \\ ${ }^{3}$ Msc, Faculty of Electrical \& Computer Engineering, Jimma Institute of Technology, Jimma, Ethiopia
}

\begin{abstract}
Liquid level control is highly important in industrial applications such as boilers in nuclear power plants. In this paper a simple liquid level tank is designed based on NARMA-L2 and Model Predictive control controllers. The simple water level tank has one input, liquid flow inn and one output, liquid level. The proposed controllers is compared in MATLAB and then simulated in Simulink to test how the system actual liquid level track the desired liquid level with two input desired signals (step and white noise). The response of the NARMA-L2 controller is then compared with a MPC controller. The results are shown sequentially and the effectiveness of the controller is illustrated.
\end{abstract}

Keywords: NARMA-L2, Model Predictive control, Simulink

\section{Introduction}

In many industrial processes, control of liquid level is required. It was reported that about $25 \%$ of emergency shutdowns in the nuclear power plant are caused by poor control of the steam generator water level. Such shutdowns greatly decrease the plant availability and must be minimized. Water level control system is a very complex system, because of the nonlinearities and uncertainties of a system. Currently, constant gain PI controllers are used in nuclear organizations for boiler water level control at high power operations. However, at low power operations, PI controllers cannot maintain water level properly. A need for performance improvement in existing water level regulators is therefore needed.

\section{Mathematical Modelling of the Tank}

Consider a tank with cross sectional area A, liquid level height $\mathrm{h}$, with fluid resistance $\mathrm{R}$, density $\rho$, volume flow in qi and volume flow out qo as shown in Figure 1 below. 


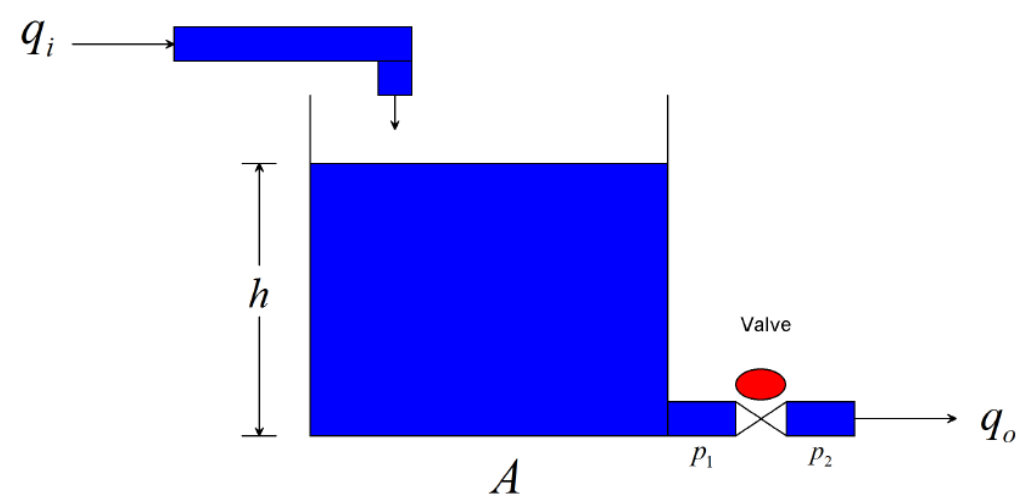

Figure 1 Water level tank system

Since $q$ i and $q$ o are the inflow and outflow respectively, and $V$ is the volume of the fluid inside the tank, we can write

$$
\frac{d V}{d t}=\frac{d}{d t}(\rho A h)=\rho q_{i}-\rho q_{o}
$$

The mass flow out can be expressed in terms of h. assume a linear model, the exit orifice resistance of the valve will be

$$
\begin{gathered}
\rho q_{o}=\frac{\Delta p}{R} \\
\rho q_{o}=\frac{\Delta p}{R}=\frac{p_{1}-p_{2}}{R}=\frac{\rho g h}{R}
\end{gathered}
$$

Assuming constant density, Substituting eqn (3) in to eqn (1) yields

$$
\rho A \frac{d h}{d t}=\rho q_{i}-\frac{\rho g h}{R}
$$

Taking Laplace transform of eqn (4), the transfer function becomes

$$
\frac{H(s)}{Q_{i}(s)}=\frac{A^{-1}}{s+\frac{g}{R A}}
$$

The parameters of the tank is shown in Table 1 below

Table 1 parameters of the tank

\begin{tabular}{|l|l|l|l|}
\hline No & Parameter & Symbol & value \\
\hline 1 & Area & A & $2 \mathrm{~m}^{\wedge} 2$ \\
\hline 2 & Density & $\rho$ & $1 \mathrm{~kg} / \mathrm{m}^{\wedge} 3$ \\
\hline 3 & Gravity & G & $10 \mathrm{~m} / \mathrm{s}^{\wedge} 2$ \\
\hline 4 & Resistance & R & $0.05 \mathrm{~s} / \mathrm{m}^{\wedge} 2$ \\
\hline
\end{tabular}


The numerical value of the system transfer function is

$$
\frac{H(s)}{Q_{i}(s)}=\frac{0.5}{s+100}
$$

\section{The Proposed Controllers}

\subsection{NARMA-L2 Control}

The neural network controller described in this section is referred to by two different names: feedback linearization control and NARMAL2 control. It is referred to as feedback linearization when the plant model has a particular form (companion form).24 It is referred to as NARMA-L2 control when the plant model can be approximated by the same form. The central idea of this type of control is to transform nonlinear system dynamics into linear dynamics by canceling the nonlinearities. This section begins by presenting the companion form system model and demonstrating how a neural network can be used to identify this model. Then it describes how the identified neural network model can be used to develop a controller. Table 2 illustrates the network architecture, training data and training parameters

Table 2 NARMA L-2 parameters

\begin{tabular}{|c|c|c|c|}
\hline \multicolumn{4}{|c|}{ Network Architecture } \\
\hline Size of hidden layer & 8 & Delayed plant input & 3 \\
\hline Sample interval(sec) & 0.01 & Delayed plant output & 3 \\
\hline \multicolumn{4}{|c|}{ Training Data } \\
\hline Training sample & 80 & Maximum Plant output & 1 \\
\hline Maximum Plant input & 2 & Minimum Plant output & 2 \\
\hline Minimum Plant input & 1 & Max interval value (sec) & 3 \\
\hline \multicolumn{3}{|c|}{ Min interval value $(\mathrm{sec})$} & 1 \\
\hline \multicolumn{4}{|c|}{ Training Parameters } \\
\hline \multicolumn{3}{|c|}{ Training Epochs } & 80 \\
\hline
\end{tabular}

\subsection{MPC Control}

The MPC Controller block receives the current measured output signal (mo), reference signal (ref), and optional measured disturbance signal (md). The block computes the optimal manipulated variables (mv) by solving a quadratic program (QP).

\section{Result and Discussion}

In this section, the comparison of the tank with the proposed controllers for tracking the desired level of the tank using step and white noise desired input signals in order to analyze which controller shows a better performance for the system with the help of Matlab/Simulink software.

\subsection{Comparison of the tank with NARMA-L2 and MPC Controllers for Tracking a Desired Step Input}


The Simulink model of the tank with the proposed controllers for tracking a desired step input signal is shown in Figure 2 below.

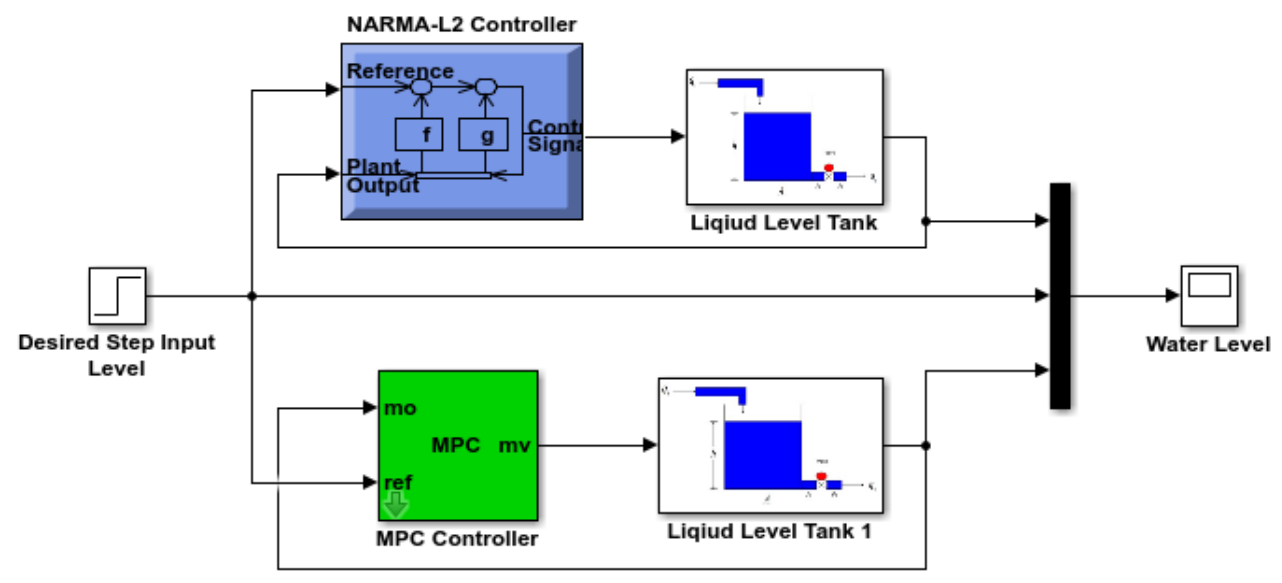

Figure 2 Simulink model of the tank with the proposed controllers for tracking a desired step input signal

The simulation result of the tank with the proposed controllers for tracking a desired step input signal is shown in Figure 3.

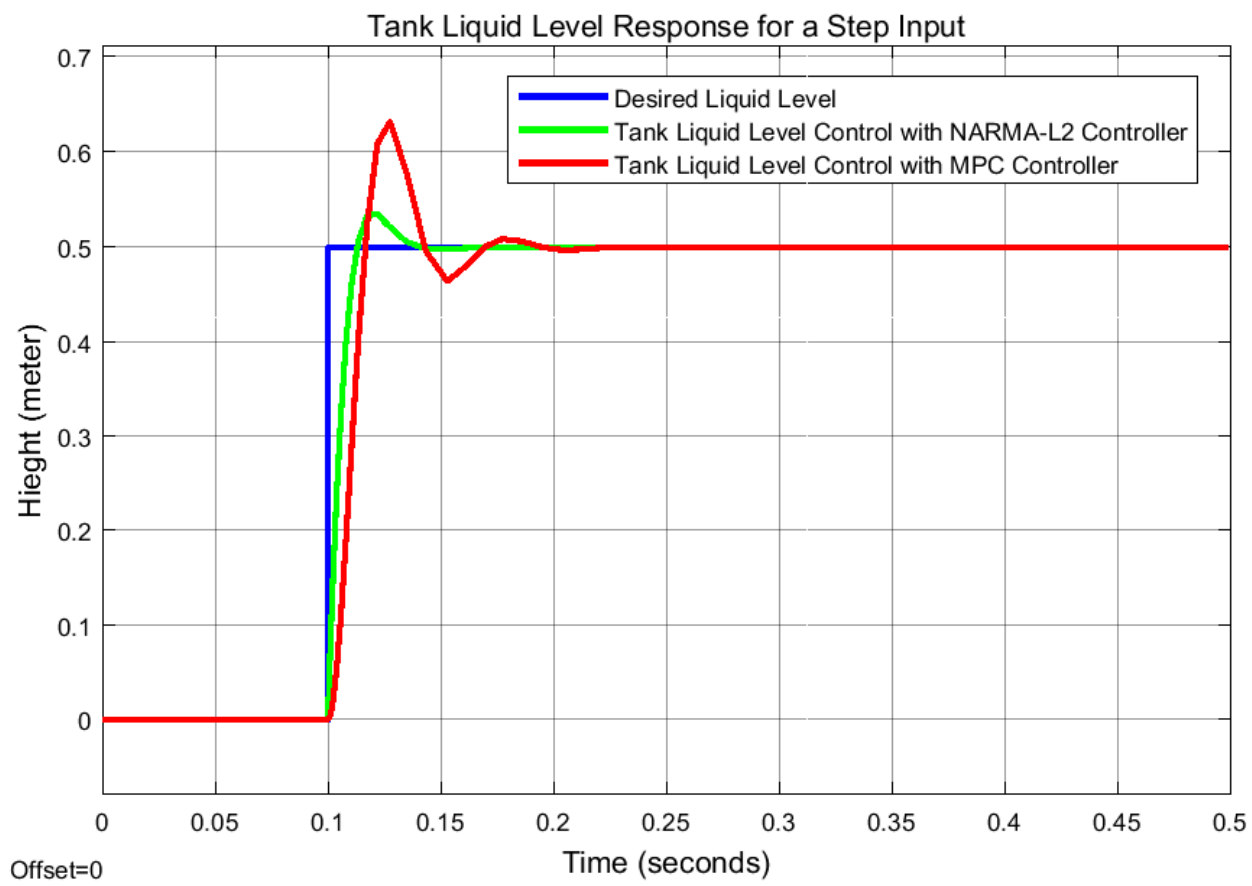

Figure 3 Simulation result of the tank level for a step input signal

The tank system with the proposed controllers Performance specification is shown in Table 3 below. 
Table 3 Performance measurement of a step response

\begin{tabular}{|l|l|l|l|}
\hline No & Performance measure & NARMA-L2 & MPC \\
\hline 1 & Rise time & $0.009259 \mathrm{sec}$ & 0.011269 \\
\hline 2 & Percentage Overshoot & $6.989 \%$ & $25.949 \%$ \\
\hline 3 & Settling time & $0.145 \mathrm{sec}$ & $0.22 \mathrm{sec}$ \\
\hline 4 & Peak value & $0.5358 \mathrm{~m}$ & $0.6327 \mathrm{~m}$ \\
\hline
\end{tabular}

As we seen from Table 3 that, the tank system with NARMA-L2 controller have better performance in all the criteria chosen.

\subsection{Comparison of the tank with NARMA-L2 and MPC Controllers for Tracking a Desired White Noise Input}

The Simulink model of the tank with the proposed controllers for tracking a desired white noise input signal is shown in Figure 4 below.

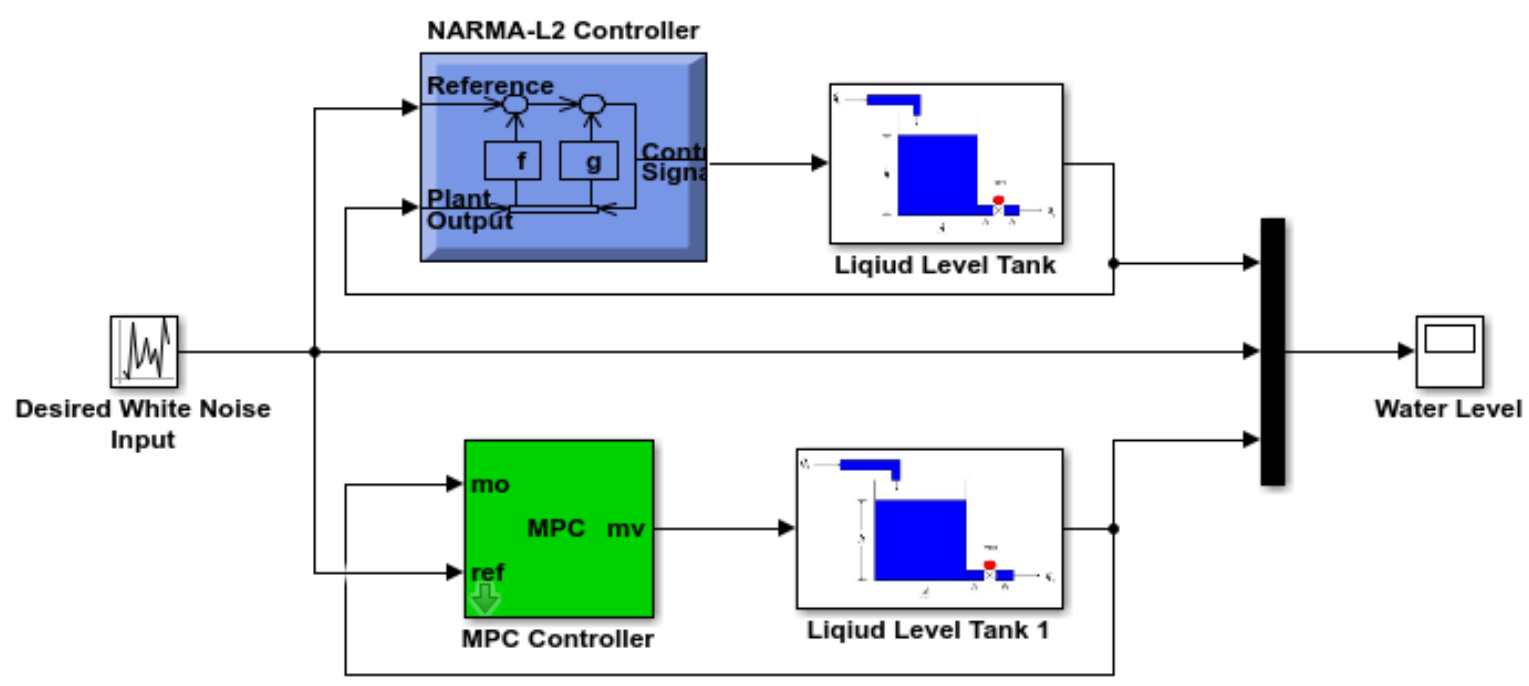

Figure 4 Simulink model of the tank with the proposed controllers for tracking a desired white noise input signal

The simulation result of the tank with the proposed controllers for tracking a desired white noise input signal is shown in Figure 5. 


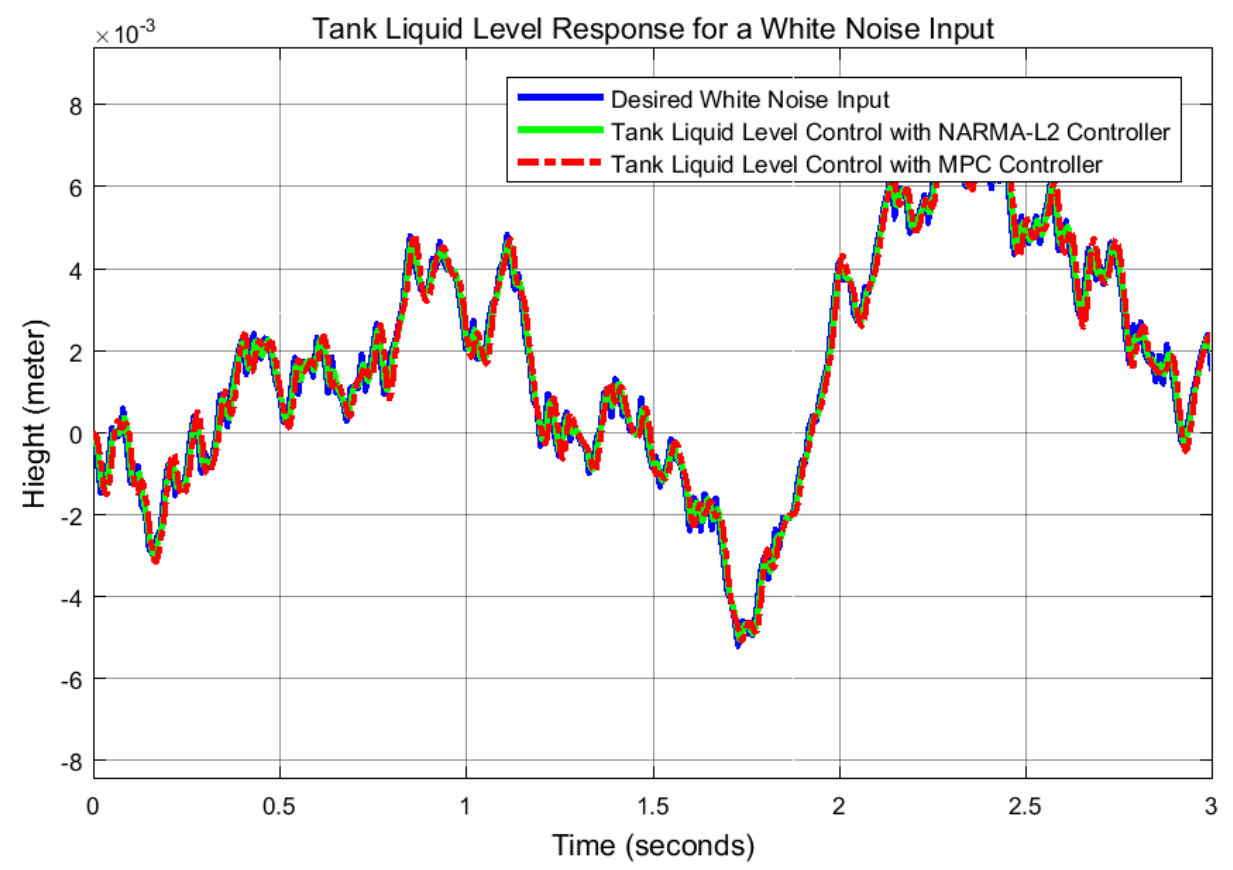

Figure 5 Simulation result of the tank level for a white noise input signal

The tank system with the proposed controller's performance specification is shown in Table 4 below.

Table 4 Performance measurement of a white noise response

\begin{tabular}{|l|l|l|l|l|}
\hline No & Performance measure & NARMA-L2 & MPC & White Noise \\
\hline 1 & Rise time & $0.057214 \mathrm{sec}$ & $0.0031578 \mathrm{sec}$ & $0.049729 \mathrm{sec}$ \\
\hline 2 & Percentage Overshoot & $88.450 \%$ & $92.113 \%$ & $105.531 \%$ \\
\hline 3 & Peak value & $1.851 \times 10^{-3} \mathrm{~m}$ & $1.589 \times 10^{-3} \mathrm{~m}$ & $1.875 \times 10^{-3} \mathrm{~m}$ \\
\hline 4 & Low value & $2.529 \times 10^{-7} \mathrm{~m}$ & $1.973 \times 10^{-4} \mathrm{~m}$ & $2.524 \times 10^{-7} \mathrm{~m}$ \\
\hline
\end{tabular}

As we seen from Table 4 that, the tank system with NARMA-L2 controller have almost the same rise time, peak value and low value as the tracked white noise input signal.

\section{Conclusions}

The liquid level tank system is designed and tested using Matlab/Simulink software and the proposed controllers is simulated successfully and the results are promising and satisfactory. Comparison of the liquid level tank system with NARMA-L2 and MPC controller is done for the step and white noise desired liquid level signals. The simulation result for the desired step desired liquid level input shows that the liquid level tank system with NARMA-L2 controller have better performance in all the criteria chosen. The simulation result for the white noise desired liquid level input shows that the liquid level tank system with NARMA-L2 controller have almost the same rise time, peak value and low value as the tracked white noise input signal. Finally, the comparative simulation result prove the effectiveness of the presented liquid level tank system with NARMA L2 controller. This neural network control approach can be used in boiler water level and also temperature control applications of nuclear/thermal power plants. As a future scope of this work, 
the NARMA-L2 controller can be implemented in a microcontroller with modified system parameters for more accurate control and can be used in various applications in industry and household. The controller can also be tested with periodically varying liquid level tracking applications.

\section{Reference}

[1]. Saunak Bhattacharya et al. "Study of a PID Control System for Liquid Level Measurement using Non-Contact Type Sensor" International Journal of Computational Intelligence \& IOT, Vol. 2, No. 3, 5 pages, 2019.

[2].Fayiz A. et al. "Active Disturbance Rejection Control of a Coupled Tank System" Journal of Engineering, Article ID 7494085, 6 pages, 2018.

[3]. Nayanmani D. et al. "PID Controller for Nonlinear Interacting Two Tank Liquid Level Control" International Journal of Development Research, Vol. 7, 8 pages, 2017.

[4].Trinh L. "Liquid Level Control of Coupled Tank System using Fuzzy-PID Controller" International Journal of Engineering Research and Technology, Vol. 06, Issue. 11, 2017.

[5].Mustafa Saad "Performance Analysis of a Nonlinear Coupled Tank System using PI Controller" Universal Journal of Control and Automation, Vol. 5, Issue. 4, pp. 55-62, 2017.

[6].K. Srinivasan et al. "Level Control of Three Tank System using Intelligent Techniques" International Journal of Image Mining, Vol. 2, Issue. 4, No. 3, 2017.

[7].C. Sreepradha et al. "Synthesis of Fuzzy Sliding Mode Controller for Liquid Level Control in Spherical Tank" Journal of Cogent Engineering, Vol. 3, Issue. 1, 2016.

[8].Mostafa A. et al. "PID Controller Design for Two Tanks Liquid Level Control System using Matlab" International Journal of Electrical and Computer Engineering (IJECE), Vol. 5, No. 3, pp.436-442, 2015. 